\title{
DESENVOLVIMENTO DA SEMENTE DE Chrysophyllum gonocarpum (MART. \& EICHL.) ENGL. (SAPOTACEAE) ${ }^{1}$
}

\author{
MARCIELE FELIPPI2; FERNANDO GROSSI³; ANTONIO CARLOS NOGUEIRA4; \\ MARIA CECÍLIA DE CHIARA MOÇO 5
}

\begin{abstract}
RESUMO - O objetivo deste trabalho foi descrever o desenvolvimento do embrião, endosperma e tegumento da semente de Chrysophyllum gonocarpum (Mart. \& Eichl.) Engl. O rudimento seminal é hemítropo. O desenvolvimento do embrião é do tipo Cariofiláceo e o endosperma é do tipo Nuclear. O embrião maduro apresenta eixo hipocótilo-radicular curto, cilíndrico e cotilédones foliáceos. A semente madura armazena grãos de aleurona e lipídios nos cotilédones e nas células remanescentes do endosperma. A exotesta é composta de diversas camadas de células esclerificadas que também recobrem a região do hilo. Esta característica da exotesta foi registrada pela primeira vez em sementes de Chrysophyllum o que demonstra que esta pode ter importância ecológica e taxonômica.
\end{abstract}

Termos para indexação: aguai, endosperma, embrião, tegumento.

\section{SEED DEVELOPMENT OF Chrysophyllum gonocarpum (MART. \& EICHL.) \\ ENGL. (SAPOTACEAE)}

\begin{abstract}
The object of this study was to describe the embryo, endosperm and integument development of Chrysophyllum gonocarpum (Mart. \& Eichl.) Engl. seed. The ovule is hemitropous, with embryo development being of the Caryophyllad type and the endosperm of the Nuclear type. The mature embryo presents a short and cylindrical hypocotyl-radicle axis with foliaceous cotyledons. The mature seed stores aleurone grains and lipids in the cotyledons and in the remaining endosperm cells. The exotesta is composed of several layers of sclerenchymatous cells, also present in the hilum region. This exotesta feature is registered for the first time in Chrysophyllum seeds and might have ecological and taxonomic implications.
\end{abstract}

Index terms: aguai, endosperm, embryo, integument.

\section{INTRODUÇÃO}

A família Sapotaceae é composta por espécies arbóreas e arbustivas, apresentam látex, e ocorrem, especialmente, em florestas úmidas, estando incluída entre as famílias mais frequentes e com maior índice de valor de importância

${ }^{1}$ Submetido em 26/06/2009. Aceito para publicação em 04/12/2009. Parte da Dissertação de Mestrado no Programa de Pós-Graduação em Engenharia Florestal da Universidade Federal do Paraná. Agradecimentos à CAPES pela concessão de bolsa ao primeiro autor.

${ }^{2}$ Doutoranda. Programa de Pós-Graduação em Engenharia Florestal da (UFSM) Universidade Federal de Santa Maria, Santa Maria, RS.Email: tanto ecológica quanto econômica na Amazônia Central (Pennington 1968; Ricardi 1992). Cerca de 40\% das sapotáceas produzem frutos comestíveis e são fornecedoras de madeira e látex, utilizados na medicina popular e ornamentação (Barbosa et al. 1977, Marchiori 2000; Kuera et al. 2002).

marciele.f@terra.com.br

${ }^{3}$ Dr., Prof. - PPGEF-UFPR. Curitiba, PR, CP 319, CEP 80210-170

${ }^{4}$ Dr., Prof. - PPGEF-UFPR. Curitiba, PR, CP 319, CEP 80210-170

${ }^{5}$ Dr., Prof. - UFRGS - Instituto de Biociências. Porto Alegre, RS, CEP 91509-900 
Chrysophyllum gonocarpum (Mart. e Eichl.)Engl., conhecida vulgarmente como gumbixava, aguai-da-serra, caxeta, mata-olho, entre outras, é uma espécie arbórea de 6-20m de altura, podendo alcançar até $60 \mathrm{~cm}$ de diâmetro na altura do peito, distribuindo-se irregularmente em fundo de vales, início de encostas e em terrenos planos, onde o solo é mais úmido (Reitz 1968; Lorenzi 2002). Por este motivo, a espécie tem sido indicada para a recuperação de ambientes ripários por estar incluída na lista de espécies em destaque devido a sua importância funcional nestes ecossistemas em vários estudos fitossociológicos, como nos trabalhos realizados por e Cavassan et al. (1984) e Bianchini et al. (2003).

Os conhecimentos relacionados aos aspectos morfológicos e anatômicos das estruturas de dispersão são fundamentais para as investigações sobre sucessão e regeneração em ecossistemas de mata nativa (Pinto et al. 2003). Os trabalhos de Corner (1976) tratam das sementes de sapotáceas descrevendo a morfologia externa da semente e do tegumento. O trabalho de Beltrati et al. (1983) descreve a estrutura anatômica das sementes de C. gonocarpum, dando ênfase à ontogênese do tegumento e as fases avançadas do desenvolvimento embrionário. No entanto, não aborda aspectos da embriogênese inicial e endospermogênese. São escassos os trabalhos sobre aspectos da embriologia na família Sapotaceae e as poucas espécies estudadas não são componentes da flora brasileira (Johri et al. 1992). Estes estudos também permitem a comparação entre os táxons e subsidiam análises filogenéticas. O objetivo deste trabalho foi estudar o desenvolvimento da semente com ênfase na embriogênese e endospermogênese, assim como características estruturais do tegumento em Chrysophyllum gonocarpum.

\section{MATERIAL E MÉTODOS}

O material botânico para o presente trabalho foi obtido no Município de Frederico Westphalen, Estado do Rio Grande do Sul, Brasil, entre setembro de 2004 e outubro de 2005. O material botânico fértil foi incorporado ao Herbário de Dendrologia, do Departamento de Engenharia Florestal, da Universidade Federal do Paraná (UFPR), com os números de registro 10027, 10028 e 10029.

Botões em pré-antese foram marcados e os eventos da antese e pós-antese foram acompanhados até a formação total do fruto. Flores em pré-antese e antese e frutos em diferentes estádios de desenvolvimento foram coletados de cinco matrizes selecionadas. O material foi fixado no campo em solução FAA70 (90 álcool: 5 ácido acético: 5 formaldeído) (Johansen 1940) e logo após foram sendo processados no Laboratório de Botânica Estrutural, do Departamento de Botânica, da Universidade Federal do Paraná (UFPR). As amostras foram desidratadas em série etílica ascendente e infiltradas em hidroxietilmetacrilato (Resina Leica) (Gerrits e Smid 1983). Os blocos foram seccionados em Micrótomo de rotação Leica RM 2145, em cortes de 2 a $8 \mu \mathrm{m}$ de espessura, corados com Azul de Toluidina $0,05 \%$, em tampão fosfato $\mathrm{pH} 6,8\left(\mathrm{O}^{\prime}\right.$ Brien et al. 1965) e montados em Permout ${ }^{\circledR}$ para observação em microscopia fotônica de campo claro. Quanto ao material para os testes histoquímicos, estes foram coletados e encaminhados diretamente ao laboratório para análise, onde foram efetuados cortes à mão livre e em seguida foram submetidos às seguintes análises: $10 \%$ solução aquosa de cloreto férrico (Johansen 1940), para localização de compostos fenólicos; floroglucinol ácido (Foster 1949), para evidenciar lignina; Sudan III (Sass 1951), para localizar lipídios; reagente de lugol (IKI) (Berlyn e Miksche 1976), para localização de amido; Comassie Blue em solução acética 7\% (Southworth 1973), para proteínas, e ao Reagente Shiff (O’Brien e McCully, 1981), para verificação de carboidratos solúveis. Para a observação de cristais utilizou-se microscopia de polarização. As análises e fotomicrografias foram realizadas no microscópio fotônico Axiolab ZEISS com câmera fotográfica digital acoplada. Para análise dos estádios iniciais da embriogênese foram feitos desenhos esquemáticos em câmara clara acoplada ao microscópio.

\section{RESULTADOS E DISCUSSÃO}

\section{Desenvolvimento do embrião}

A embriogênese inicial em C. gonocarpum está esquematizada na Figura 1 (A-F). O zigoto, logo após a fecundação, encontra-se junto à micrópila (Figura 2). Posteriormente, torna-se polarizado com o núcleo e grande parte do citoplasma, no pólo calazal, e um grande vacúolo, no pólo micropilar (Figura 1A). Este vacúolo aumenta de volume e esta região da célula zigótica torna-se afilada e longa, consequentemente, direcionando o pólo calazal com o núcleo para a região central do tecido endospérmico (Figura 1B e 3). Neste local, o zigoto sofre uma divisão transversal desigual originando a célula basal micropilar maior (cb) e a célula terminal calazal menor (ca) (Figura 1C e 4). A ca divide-se transversalmente originando uma célula micropilar 
(cd) e outra calazal (cc) (Figura 1D e 5). Sucessivamente, outras divisões celulares, transversais e longitudinais, nas células do pró-embrião dão origem as fileiras ci, m, 1 e l', todas derivadas da ca (Figura 1E, 1F, 6). O suspensor é formado pela cb, que não se divide, e por células derivadas das fileiras ci e $\mathrm{m}$ (Figura 7). As células do suspensor se diferenciam das células do embrião por apresentarem maior volume, presença de um grande vacúolo e um núcleo periférico (Figura 7 e 8).
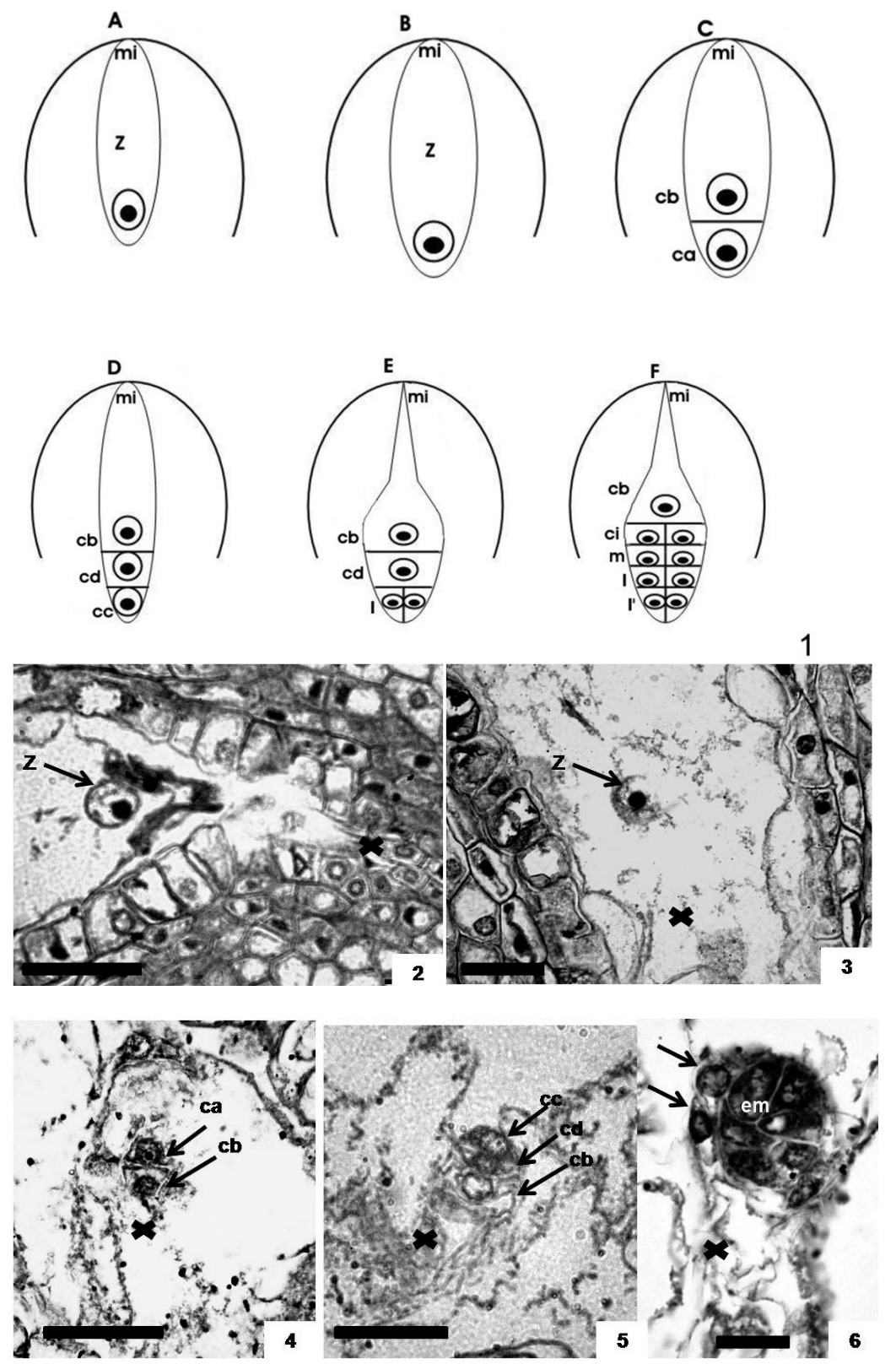

FIGURA 1-6. Embriogênese inicial em Chrysophyllum gonocarpum (Mart. \& Eichl.) Engl.. 1. Desenho esquemático das etapas da embriogênese inicial. A. Zigoto; B. Polarização e aumento de volume do zigoto; C. Divisão transversal desigual originando a célula terminal (ca) e a célula basal (cb); D. Divisão transversal da ca originando as células ed e cc; $\mathbf{E}$. Divisão longitudinal da ce originando a fileira de células l; F. Divisões transversais e longitudinais originando as fileiras ci, $\mathrm{m}, \mathrm{l}$ e l'. 2. Zigoto localizado na região micropilar; 3. Zigoto localizado na região central do tecido endospérmico; 4 . pró-embrião formado pela célula basal e terminal (cb e ca); 5. Pro-embrião tricelular formado por cb e as células cd e cc; 6. Pró-embrião multicelular com núcleos do endosperma ao seu redor (setas). Barra de escala $=50 \mu \mathrm{m}$. 


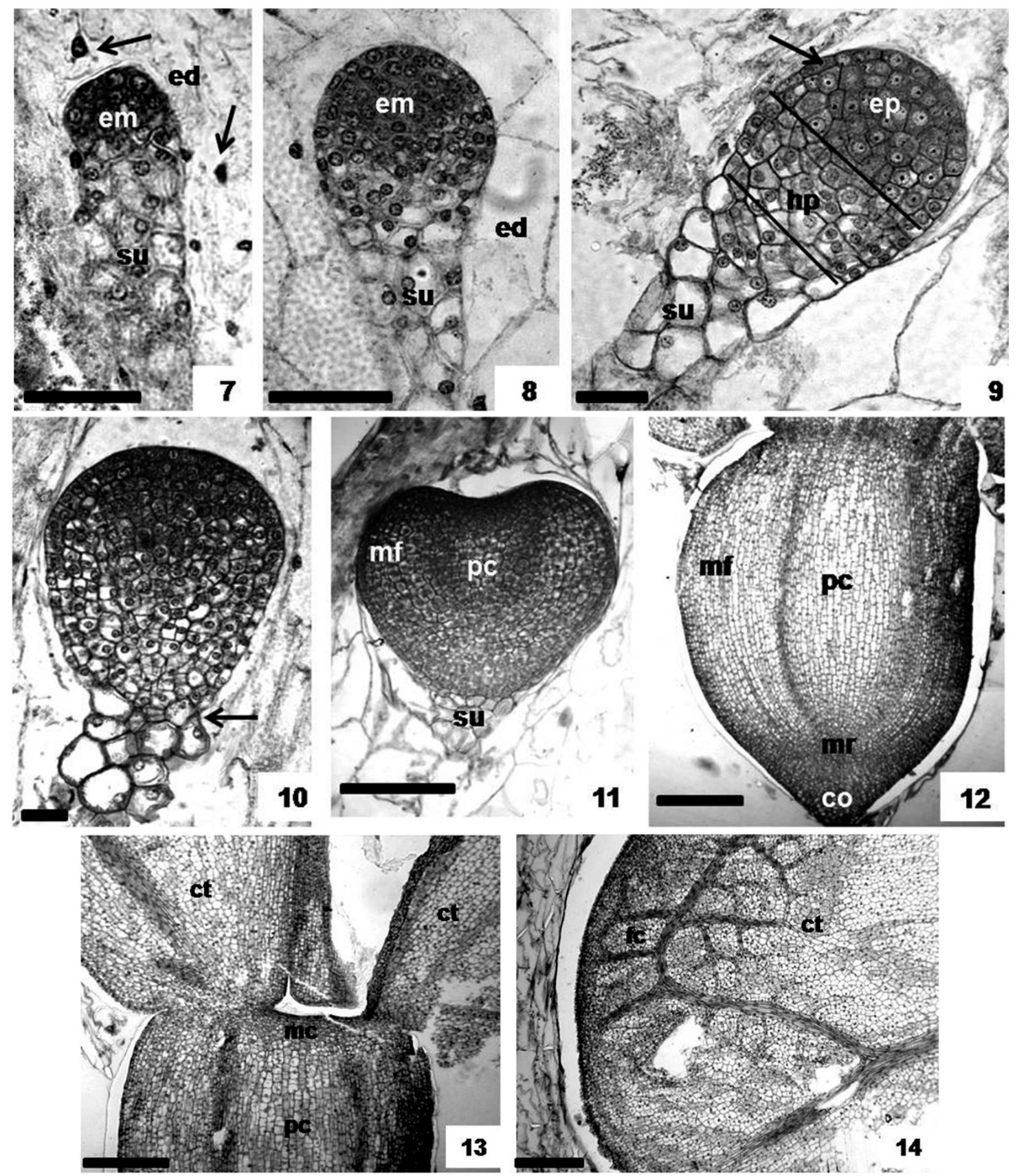

FIGURA 7-14. Embriogênese em Chrysophyllum gonocarpum (Mart. \& Eichl.) Engl.. 7. Embrião com suspensor multicelular e endosperma cenocítico com diversos núcleos (setas); 8. Embrião imerso no tecido do endosperma celularizado; 9. Embrião no estádio globular com formação de protoderme e distinção das regiões epifisal e hipofizal. 10. Embrião na fase de mudança de simetria e constrição da região hipofizal (seta). 11. Embrião cordiforme com distinção do procâmbio e meristema fundamental; 12. Detalhe do eixo hipocótilo-radicular no embrião maduro; 13. Detalhe da região do meristema apical caulinar no mesmo estádio anterior; 14. Detalhe dos feixes procambiais no cotilédone do embrião maduro. $C o=$ coifa; ct $=$ cotilédone; $\mathbf{e d}=$ endosperma; $\mathrm{em}=$ embrião; $\mathrm{ep}=$ região epifisal; $\mathrm{fc}-$ feixe vascular procambial; $\mathbf{h p}$ $=$ região hipofisal; $\mathbf{m c}=$ meristema apical caulinar $\mathbf{m f}=$ meristema fundamental; $\mathbf{m r}=$ meristema apical da raiz; $\mathbf{p c}=$ procâmbio; $\mathbf{s u}=$ suspensor. $\mathbf{O}$ asterisco representa a região micropilar. Barra de escala=50 $\mu \mathrm{m}$ em 6 e 7 e $100 \mu \mathrm{m}$ nas outras figuras. 
O proembrião passa por um período de proliferação celular, mantendo-se com simetria radial e atinge o estádio globular, após três meses de desenvolvimento, com a organização das células da protoderme (Figura 9). Neste momento, ocorre uma diferenciação celular marcando duas regiões tissulares: região epifisal, distal ao suspensor, composta de células menores com citoplasma denso, e uma região hipofisal, com células maiores e vacuoladas. Durante a transição do estádio globular para o cordiforme, nota-se um alargamento na região epifisal, uma constrição na região hipofisal e a mudança da simetria radial para a bilateral (Figura 10). O embrião inicia a emissão dos cotilédones, caracterizando o embrião de estádio cordiforme, aos quatro meses de desenvolvimento (Figura 11). Nesta fase, já se diferencia uma região procambial e o meristema fundamental. Por volta do quinto mês, aumenta o volume dos cotilédones e do eixo hipocótilo-radícula, caracterizando a fase de embrião cotiledonar (Figuras 12,13 e 14). O embrião maduro axial apresenta um eixo hipocótilo-radicular curto e cilíndrico protegido por uma coifa pouco desenvolvida (Figura 12). O meristema apical caulinar é composto de poucas fileiras de células, não desenvolvendo nenhum primórdio foliar (Figura 13). Os cotilédones são foliáceos com vascularização ramificada (Figura 14). As células do mesofilo dos cotilédones permanecem indiferenciadas com aspecto homogêneo (Figura 14). Os testes histoquímicos identificaram a presença de grãos de aleurona e lipídios nas células do mesofilo dos cotilédones.

O rudimento seminal na família Sapotaceae apresenta variações do anátropo ao hemítropo (Lawrence 1966; Corner 1976; Johri et al. 1992; Cronquist 1988). A compreensão da curvatura anátropa durante o desenvolvimento do rudimento seminal é essencial para entender a estrutura da semente (Boesewinkel e Bouman 1984). O rudimento seminal de C. gonocarpum foi, anteriormente, interpretado como do tipo anátropo por Beltrati et al. (1983). No entanto, neste trabalho, foi caracterizado como do tipo hemítropo (Figura 15), de acordo com a classificação de Bouman (1984). Cronquist (1988) caracteriza a posição do rudimento seminal, em relação à placenta, como apótropo na família Sapotaceae, porém o rudimento seminal em C. gonocarpum é epítropo, com a micrópila voltada para cima e rafe interna.

Diversos embriologistas sugeriram sistemas de classificação da embriogênese para as angiospermas (Natesh e Rau 1984). Consequentemente, cada embriologista segue um sistema diferente de acordo com sua própria interpretação, o que gera conflitos de terminologia e muita dificuldade para estabelecer comparações úteis para análises filogenéticas. $\mathrm{Na}$ obra de Johri et al. (1992), a embriogênese na ordem Ebenales, onde a família Sapotaceae está inserida, segue uma classificação adaptada do sistema de Yamazaki (1970, citado por Johri et al. 1992). Nesse trabalho, a embriogênese de C. gonocarpum se encaixa no tipo Cariofiláceo, segundo a classificação de Johansen (1950). A única espécie de Sapotaceae com embriogênese descrita por Yamazaki foi Pouteria obovada var. dubia. Baseando-se na tradução e classificação feita por Jorhi et al. (1992), para embriogênese, nesta pesquisa C. gonocarpum se enquadra na embriogênese do tipo Cariofiláceo. Neste tipo, a célula basal não participa da formação do embrião propriamente dito e origina somente o suspensor. No entanto, de acordo com o trabalho original de Johansen (1950), o tipo Cariofiláceo pode ocorrer tanto em dicotiledôneas quanto em monocotiledôneas e pode apresentar até 13 variações.

Swamy e Padmanabhan (1962) criticam estes sistemas de classificação baseados na seqüência de divisões celulares e o destino das camadas na embriogênese inicial. De acordo com estes autores, estudos comparativos demonstraram que existe uma grande plasticidade no desenvolvimento, na histogênese e na organogênese embrionária e que somente mais tarde no estádio globular é que as diferenças fundamentais aparecem. O estudo de Scheres et al. (1994) comprova que as células do proembrião originam determinadas partes, e sempre as mesmas, no corpo do embrião maduro. Este estudo confirma a importância de se acompanhar as divisões celulares durante o desenvolvimento embrionário e de toda a argumentação feita por Johansen (1945) em defesa dos estudos embriológicos comparativos.

\section{Desenvolvimento do endosperma}

O endosperma é do tipo Nuclear. O núcleo endospérmico se divide e dá origem a um cenócito (Figura 6 e 7). A celularização do endosperma se inicia na região micropilar, pouco antes da caracterização do estádio globular (Figura 8) e, lentamente, o processo alcança a região calazal.

Diversos autores citam a ocorrência de endosperma do tipo nuclear na família sapotáceae (Corner 1976; Cronquist 1981, 1988; Johri et al. 1992), sendo que Jorhi et al. (1992) apontam que esta característica diferencia esta família das outras da Ordem Ebenales. 


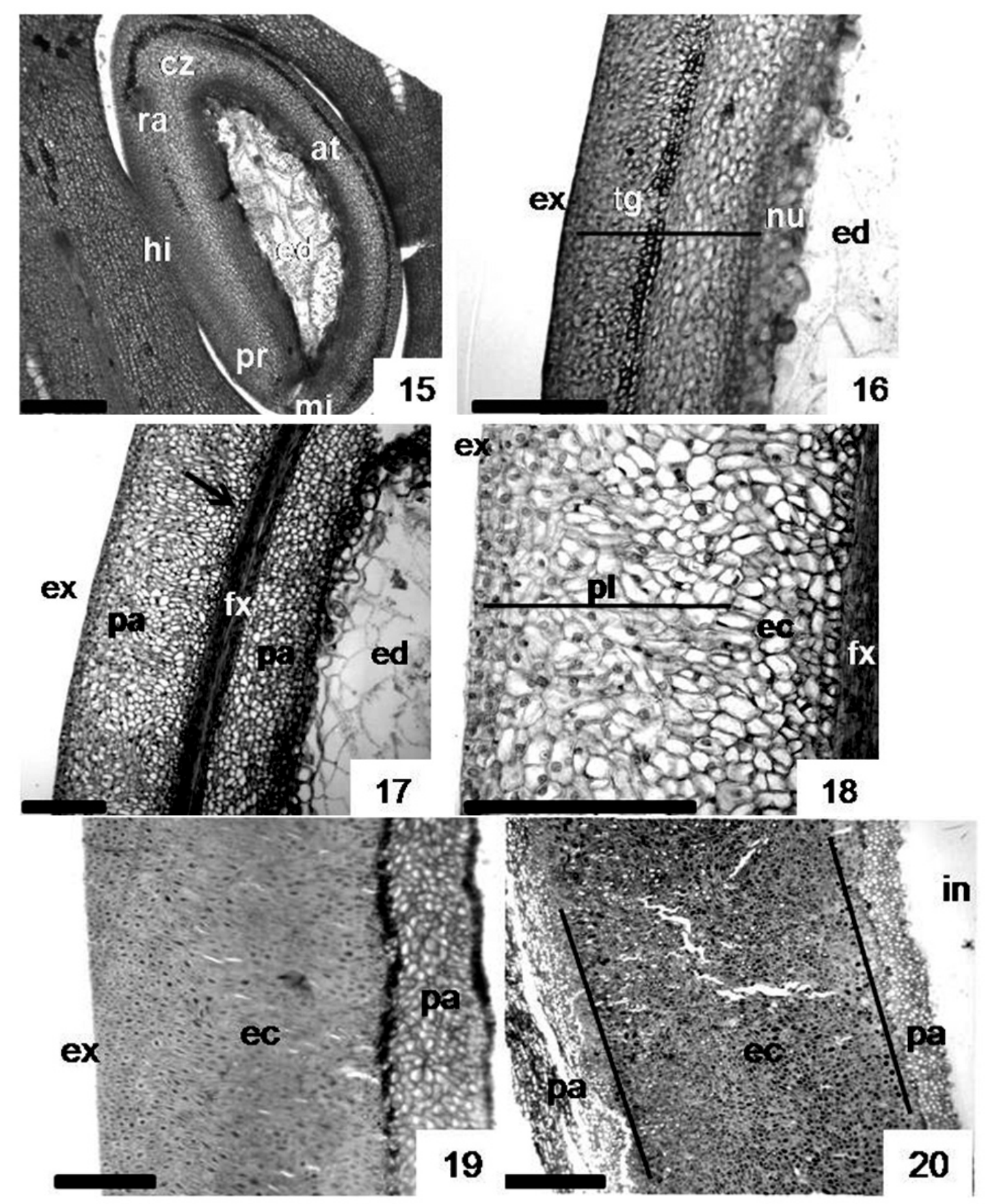

FIGURA 15-20. Formação do tegumento da semente em Chrysophyllum gonocarpum (Mart. \& Eichl.) Engl. 15. Corte longitudinal do fruto jovem com rudimento seminal hemítropo no estágio inicial da embriogênese. 16. Tegumento da semente jovem com camadas de esclereídes na região mediana. 17. Tegumento da semente jovem com a região de esclerificação próxima ao feixe vascular. 18. Detalhe da figura 17 com a região de proliferação superficial do tegumento. 19. Tegumento da semente madura com dois estratos de células na região oposta ao hilo. 20. Tegumento da semente madura com três estratos na região do hilo. at $=$ anterafe; $\mathrm{cz}=$ calaza; ed $=$ endosperma; ec $=$ esclerênquima; $\mathbf{h i}=$ hilo; in = face interna do tegumento; $\mathrm{ex}=$ face externa do tegumento; $\mathbf{f x}=$ feixe vascular; $\mathbf{m i}=$ micrópila; $\mathbf{n u}=$ nucelo; $\mathbf{p a}=$ parênquima; $\mathbf{p l}=\mathbf{z o n a}$ de proliferação celular; $\mathrm{pr}=$ pré-rafe; $\mathrm{ra}=\mathrm{rafe} ; \mathrm{tg}=$ tegumento. Barra de escala $=\mathbf{2 0 0 \mu \mathrm { m }}$ 
Para a espécie em estudo, na semente madura, o endosperma é abundante, uniforme, de coloração branca, e consta de um número variável de camadas de células poliédricas (Figura 17) que acumulam grãos de aleurona e lipídios.

Beltrati et al. (1983), descrevem a presença de incrustações de cristais de oxalato de cálcio nas paredes celulares das células do endosperma e embrião em C. gonocarpum. No entanto, estes cristais não foram identificados no material observado neste trabalho. A formação de cristais em paredes celulares foi registrada também em embriões de soja (Ilarslan et al. 2001). Nas células destes embriões, os componentes da parede celular são depositados em volta do vacúolo que contém o cristal e, consequentemente, o crescimento da parede recobre este vacúolo com a fusão das membranas (tonoplasto e membrana celular). A função destes cristais no embrião ainda permanece desconhecida. No entanto, a divergência entre os resultados de Beltrati et al. (1983) e os resultados obtidos neste trabalho sugerem que o controle da cristalização seja influenciado por fatores externos (concentração de cálcio no solo, por exemplo).

\section{Desenvolvimento do tegumento da semente}

O feixe vascular rafeal percorre a curta rafe e se ramifica em diversos feixes pós-calazais que convergem na região da micrópila (Figura 15). O tegumento do rudimento seminal, logo após a fecundação, apresenta cerca de $60 \mu \mathrm{m}$ e é composto por um tecido parenquimático (Figura 15 e 16). O tegumento parenquimático é dividido em duas faces: externa e interna, através de duas fileiras de esclereídes que acompanham os feixes vasculares (Figura 15 e 16).

Conforme trabalho de Felippi et al. (2008) sementes de C. gonocarpum possuem germinação lenta e desuniforme, demonstrando, portanto, a necessidade de maiores estudos para acelerar, uniformizar ou até mesmo estabelecer a germinação. A partir das informações contidas neste trabalho e segundo a descrição de Felippi et al. (2008), sugere-se que a presença de parede esclerificada na região hilar pode estar relacionada a dormência tegumentar, prejudicando o índice germinativo.

No estádio globular do embrião, as células da epiderme e parenquimáticas mais externas se dividem em diversos planos aumentando a espessura do tegumento (Figura 17 e 18). Conforme o embrião se desenvolve, a lignificação ocorre nas células próximas ao feixe vascular em direção à superfície externa do tegumento (Figura 19). A semente exotestal madura apresenta dois estratos contínuos na região anti-rafe: o externo, com cerca de 20 a 30 camadas de células esclerificadas e o interno, com cerca de 8 a 12 camadas de células parenquimáticas ricas em compostos fenólicos (Figura 19). Na região do hilo, o tegumento apresenta três estratos: o externo, parenquimático; o mediano, esclerificado contínuo com a exotesta, e o interno, parenquimático contínuo por toda a região interna da semente (Figura 20).

Corner (1976) descreve e ilustra o tegumento de Chrysophyllum cainito L. e C. roxburghii G. Don. Este autor destaca que o tecido interno do tegumento na região do hilo nestas espécies apresenta células com paredes espessadas, mas não-lignificadas. No entanto, os resultados obtidos com C. gonocarpum neste trabalho demonstram uma continuidade do tecido esclerificado do tegumento também na região do hilo, concordando com o que já foi descrito por Beltrati et al. (1983) para a mesma espécie.

A semente madura é definida como do tipo hilar, pela presença de hilo extenso, de acordo com a classificação de Boesewinkel \& Bouman (1984). A família Sapotaceae foi considerada monofilética, de acordo com análises moleculares de seqüências rbcL de Morton et al. (1996). Estes Autores apontam que as características do hilo são sinapomorfias. Estas diferenças podem ter um papel ecológico e fisiológico na germinação da semente e devem ser mais bem investigadas em outras espécies.

\section{CONCLUSÕES}

Em C. gonocarpum, a embriogênese é do tipo Cariofiláceo, rudimento seminal do tipo hemítropo e o endosperma do tipo Nuclear. Na semente madura, o endosperma é celularizado com reserva de grãos de aleurona e lipídios. A presença de cristais de oxalato de cálcio no embrião e endosperma é considerada uma característica variável na espécie. A estrutura do hilo apresenta particularidades que variam dentro do gênero Chrysophyllum e podem ter papel importante na germinação da semente.

\section{AGRADECIMENTOS}

A Capes, pela bolsa concedida; à URI, pelo uso dos laboratórios e ajuda dos funcionários para a coleta de material botânico; ao técnico Nilson Belém Filho, do Laboratório de Botânica Estrutural (UFPR), pelo auxílio nos trabalhos laboratoriais. 


\section{REFERÊNCIAS}

BARBOSA, O.; BAITELLO, J.B.; MAINIERI, C.; MONTAGNA, R.G.; NEGREIROS, O.C. de, Identificação e fenologia de espécies arbóreas da Serra da Cantareira (São Paulo). Revista do Instituto Florestal, v.11, p.1-168, 1977.

BELTRATI, C.M.; BARALDI, M.B.G.; PAGANO, S.N. Estudo morfoanatômico das sementes de Chrysophyllum gonocarpum (Mart. \& Eichl.) Engler (Sapotaceae). Naturalia, v.8, p.159-167, 1983.

BERLYN, G.P.; MIKSCHE, J.P. Botanical microtechnique and cytochemistry. Ames, The lowa Satate Press, 1976.326 p.

BIANCHINI, E.; POPOLO, R.S.; DIAS, M.C.; PIMENTA, J.A. Diversidade e estrutura de espécies arbóreas em área alagável do município de Londrina, Sul do Brasil. Acta Botânica Brasileira, v.17, n.3, p.405-419, julho/set. 2003.

BOESEWINKEL, F.D.; BOUMAN, F. 1984. The seed: structure. In: JOHRI, B.M. (Ed.). Embriology of angiosperms. Berlin: Springer-Verlag. 1984, p. 567-610.

Embriology of angiosperms. Berlin, Springer-Verlag.

BOUMAN, F. The ovule. In: In: JOHRI, B.M. (Ed.). Embriology of angiosperms. Berlin: Springer-Verlag. 1984, p.123-157.

CAVASSAN, O.; CESAR, O.; MARTINS, F.R. Fitossociologia da vegetação arbórea da Reserva Estadual de Bauru, Estado de São Paulo. Revista Brasileira de Botânica, v.7, n.2, p.91-106, 1984.

CORNER, E.J.H. The Seeds of Dicotyledons. London: Cambridge University Press, v.1, 1976. 311p.

CRONQUIST, A. The Evolution and Classification of flowering plants. 2. ed. Bronx: New York Botanical Garden, 1988. 555p.

CRONQUIST, A. An Integrated system of classification of flowering plants. New York: Columbia University Press, 1981. 501p.

FOSTER, A.S. Pratical plant anatomy. Princeton, D. van Nostrand Company Inc., 1949.

FELIPPI, M; GROSSI, F.; NOGUEIRA, A.C.; KUNIYOSHI, Y.S. Fenologia e germinação de sementes de aguai, Chrysophyllum gonocarpum (Mart. \& Eichl.) Engl. Revista Floresta, v.38, n.2, abr./jun. 2008.

GERRITS, P.O.;SMID, L. A new, less toxic polymerization system for the embedding of soft tissues in glycol methacrylate and subsequent preparing of serial sections. Journal of Microscopy, v.132, n.1, p.81-85, 1983.
ILARSLAN, H.; PALMER, R.G.; HORNER, H.T. 2001. Calcium oxalate crystals in developing seeds of soybean. Annals of Botany, v.88, p.243-257, 2001.

JOHANSEN, D.A. Plant microtechnique. New York: McGraw-Hill Book Company, 1940. 523p.

JOHANSEN, D.A. Plant Embryology: embryogeny of the Spermatophyta. Walttham: Massachusettes, 1950. 298p.

JOHANSEN, D.A. A critical survey of the present status of plant embryology. The Botanical Review, v.11, n.2, p.87107, 1945.

JOHRI, B.M.; AMBEGAOKAR, K.B.; SRIVASTAVA, P.S. Comparative Embryology of Angiosperms. v.2, 1992. $1221 \mathrm{p}$.

KUERA, N.Y.M.; LOPEZ, J.A.; LITTLE, JR.E.L.; RITZ, G.F.; ROMBOLD, J.S.; HAHN, W.J. Arboles Comues Del Paraguay. Cuerpo de Paz, Colección e Intercambio de Información, 2.ed., Octubre 2002. 458p.

LAWRENCE, G.H.M. Taxonomy of vascular plants. The Macmillan Company: New York, 1966. 823p.

LORENZI, H.; Árvores brasileiras: manual de identificação e cultivo de plantas arbóreas nativas do Brasil. São Paulo. Nova Odessa,: Editora Plantarum, v.1, 4.ed., 2002. 368p. Natesh \& Rau 1984.

NATESH, S.; RAU, M.A. The embryo. In: JOHRI, B.M. (Ed.). Embryology of angiosperms. Berlin: SpringerVerlag. 1984, p.377-443.

MARCHIORI, J.N.C. Dendrologia das Angiospermas - das Bixáceas às Rosáceas. Santa Maria: Editora UFSM, 2000. 240p.

MORTON, C.M.; CHASE, M.W.; KRON, K.A.; SWENSEN, S.M.. A molecular evaluation of the monophyly of the order Ebenales based upon $r b c \mathrm{~L}$ sequence data. Systematic Botany, v.21, p.567-586, 1996.

O' BRIEN, T.P.; MCCULLY, M.E. The study of plant structure principles and selected methods. Melbourne, Termarcarphi Pty. Ltd. 1981. 345 p.

O' BRIEN, T.P.; FEDER, N.; MCCULLY, M.E. Polychromatic staining of plant cell walls by toluidine blue O. Protoplasma, v.59, n.2, p.368-373, 1965.

PENNINGTON, T.D. Flora Neotropica, Monograph 52, Sapotaceae. New York: Published for Organization for flora Neotropica by the New York Botanical Garden, 1968. 770p.

PINTO, D.D.; MOURÃO, K.S.M.; SOUZA, L.A. de; MOSHETA, I.S. Morfo-anatomia do fruto e da semente em 
desenvolvimento de Guarea macrophylla Vahl. (Meliaceae). Acta Cientifica Venezolana, v.54, p.238-246, 2003.

REITZ, P.R. Flora Ilustrada Catarinense: Sapotáceas. Itajaí $-\mathrm{SC}, 1968.72 \mathrm{p}$

RICARDI, S.M.H. Famílias de Dicotiledôneas Venezolonas I. Mérida - Venezuela, MCMXCII,1992. 170 p.

SASS, J. E. Botanical microtechnique. 2.ed. Ames: The Iowa State College Press, 1951. 391p.

SCHERES, B.; WOLKENFELT, H.; WILLEMSEN, V.; TERLOUW, M.; LAWSON, E.; DEAN, C.; WEISBEEK, P.. Embryonic origin of the Arabidopsis primary root and root meristem initials. Development, v.120, p. 2475-2487, 1994.
SOUTHWORTH, D. Cytochemical reativity of pollen walls. Journal of Histochemistry and Cytochemistry, v.21, p.7380, 1973.

SWAMY, B.G.L.; PADMANABHAN, D. A reconnaissance of angiosperm embryogenesis. Journal of Indian Botanical Society, v.41, p.422-437, 1962.

YAMAZAKI, T. Embryological studies in Ebenales. Sapotaceae. Japanese Journal of Botany, v.46, p.161-166, 1970. 